Research article

\title{
Cytochrome P450 metabolism-based herbicide resistance to imazamox and 2,4-D in Papaver rhoeas
}

\author{
Joel Torra $^{\mathrm{a}, *, 1}$, Antonia María Rojano-Delgado ${ }^{\mathrm{b}, 1}$, Julio Menéndez ${ }^{\mathrm{c}}$, Marisa Salas ${ }^{\mathrm{d}}$, \\ Rafael de Prado ${ }^{\mathrm{b}}$ \\ a Department d'Hortofructicultura, Botànica i Jardineria, Agrotecnio, Universitat de Lleida, 25198, Lleida, Spain \\ ${ }^{\mathrm{b}}$ Department of Agricultural Chemistry and Soil Science, University of Córdoba, Campus Rabanales, 14014, Córdoba, Spain \\ ${ }^{c}$ Departamento de Ciencias Agroforestales, Escuela Politécnica Superior, Campus Universitario de La Rábida, 21071, Palos de la Frontera, Huelva, Spain \\ d Crop Protection, Corteva Agriscience, 782808, Guyancourt, France
}

\section{A R T I C L E I N F O}

\section{Keywords:}

ALS inhibiting herbicides

Cross-resistance

Enhanced metabolism

Imazamox

P450 inhibitor

Synthetic auxin herbicides

\begin{abstract}
A B S T R A C T
Papaver rhoeas biotypes displaying multiple herbicide resistance to ALS inhibitors and synthetic auxin herbicides (SAH) are spreading across Europe. In Spain, enhanced metabolism to imazamox was confirmed in one population, while cytochrome-P450 (P450) based metabolism to 2,4-D in another two. The objectives of this research were to further confirm the presence of P450 mediated enhanced metabolism and, if so, to confirm whether a putative common P450 is responsible of metabolizing both 2,4-D and imazamox. Metabolism studies were undertaken in five $P$. rhoeas populations with contrasted HR profiles (herbicide susceptible, only HR to ALS inhibitors, only HR to SAH, or multiple HR to both), and moreover, three different P450 inhibitors were used. The presence of enhanced metabolism to these SoA was confirmed in three more HR $P$. rhoeas populations. This study provides the first direct evidence that imazamox metabolism in these biotypes is P450-mediated, also in one population without an altered target site. Additionally, it was further confirmed that enhanced metabolism of 2,4-D in biotypes only HR to SAH or multiple HR to ALS inhibitors and SAH involves P450 as well. No metabolism was detected using the three inhibitors in all the herbicide-metabolizing $P$. rhoeas biotypes, suggesting that a common metabolic system involving P450s is responsible of degrading herbicides affecting both SoAs. Thus, selection pressure with either SAH or imidazolinone ALS inhibitors can select not only for resistance to each of them, but it can also confer cross-resistance between them in $P$. rhoeas.
\end{abstract}

\section{Introduction}

Non-target site resistance (NTSR) is any mechanism not related with the herbicide target in contrast with target site resistance (TSR). NTSR encompasses all mechanisms that minimize herbicide injury in weeds by reducing toxic concentrations at herbicide sites of action (SoA) such as reduced absorption, impaired translocation, sequestration, metabolism allowing biochemical modification, decreased activation rates, and protection/recovery from damage (Délye et al., 2013). The most concerning type of NTSR in herbicide resistant (HR) weeds are enhanced rates of herbicide metabolism, because they may confer cross-resistance to herbicides with different SoA (Rigon et al., 2020). Herbicide detoxification can schematically occur in a four-phase schema: degradation in phase I (typically oxidation), conjugation in phase II, transport in phase
III (vacuole or extracellular space) and further degradation in phase IV (Yuan et al., 2007). Constitutive enzymatic super families are responsible for these different four phases: e.g., cytochrome P450 mono-oxygenases (P450s) in phase I, glutathione-S-transferases (GSTs) and glucosyltransferases (GTs) in phase II, and ABC transporters in phase III, and others (Gaines et al., 2020).

P450s are probably the most researched detoxifying enzymes in HR weeds up-to-date and they play a primary role in the Phase I metabolism of herbicides. The first evidence for plant P450 involvement in herbicide metabolism was already reported in 1969 (Frear et al., 1969). Plants possess hundreds of P450s from this enzyme superfamily that catalyse a wide array of reactions with different substrate specificities (Werck-Reichhart and Feyereisen, 2000). P450s can confer NTSR to weeds by means of enhanced degradation rates to several SoA (Siminszky, 2006).

\footnotetext{
* Corresponding author. Department D’Hortofructicultura, Botànica i Jardineria, Agrotecnio, Universitat de Lleida, Alcalde Rovira Roure 191, Lleida, Spain.

E-mail address: joel.torra@udl.cat (J. Torra).

1 The first two authors equally contributed to this research.
} 
Moreover, P450s are also involved in metabolic cross-resistance to herbicides with different SoA, complicating the management of weed populations with this NTSR mechanism which is a major threat to global food production (Yu and Powles 2014a; Yuan et al., 2007).

Enhanced metabolism conferring resistance to acetolactate synthase (ALS) inhibiting herbicides mediated by P450s has been documented in several weeds, particularly in grasses but also broadleaf weeds (Jugulam and Shyam, 2019). In the case of synthetic auxin herbicides (SAHs), NTSR by means of enzymes that metabolize them is more rare (Busi et al., 2018). Few cases have reported the potential role of P450s in the degradation of SAH in HR broadleaf weeds (Torra et al., 2017; Figueiredo et al., 2018; Shergill et al., 2018; Gaines et al., 2020; Palma-Bautista et al., 2020; Todd et al., 2020).

Classically, metabolic resistance endowed by P450s has been indicated indirectly by the use of P450 inhibitors at the whole plant level or directly by enhanced metabolism rates of herbicides (Siminszky, 2006). More recently, P450-mediated metabolic resistance is being confirmed and gens identified thanks to molecular biology and new genomic technologies. The role of P450s in metabolic resistance has been known at the whole plant level for decades since late ' 80 s (Kemp and Caseley, 1987), and using different $P 450$ inhibitors also allows understanding if common P450s are involved in cross-resistance to different SoAs (Preston et al., 1996). These P450s inhibitor studies can indicate, not only the involvement of P450s in metabolic resistance, but also if different P450s are responsible of degrading different SoA when differential phenotypic responses are obtained using several P450 inhibitors (reviewed in Gaines et al., 2020). For example, the P450 inhibitor malathion restored chlorsulfuron activity in multiple HR Lolium rigidum (Preston et al., 1996), or 2,4-D activity in HR P. rhoeas (Torra et al., 2017), whereas malathion, amitrole, and piperonyl butoxide (PBO), the most used P450 inhibitors, restored the activity of tembotrione and topramezone in HR Amaranthus tuberculatus (Oliveria et a., 2018). However, the P450 inhibitors can have specificity for P450 isoforms. Pre-treatment with PBO, but not malathion, synergized with fenoxaprop in HR Poa annua (Gaines et al., 2020). Less common are studies that combine metabolism experiments and inhibitors to demonstrate that metabolic resistance can be endowed by P450s in grasses (Hall et al., 1995; Hyde et al., 1996; Singh et al., 1998; Yasuor et al., 2009), and particularly far less common in broadleaf weeds (Figueiredo et al., 2018; Ma et al., 2013). For instance, 2,4-D metabolism was inhibited with malathion in a SAH resistant $A$. tuberculatus population (Figueiredo et al., 2018). These inhibitors can inhibit the P450 metabolism of several classes of herbicides (ACCase, ALS, HPPD, PPO, PSII, SAH, carotenoid synthesis inhibitors, etc.). When using different P450 inhibitors in such studies, inhibition patterns can be not only herbicide specific, but probably also species-specific. To the best of our knowledge there is only a single study combining metabolism experiments with different P450s inhibitors to understand if common or different enzymes are responsible of degrading herbicides from different SoAs. On the other hand, in that study only the rate of herbicide metabolism was estimated but not each of the metabolites (Preston et al., 1996).

In Spain, multiple HR P. rhoeas populations to ALS inhibiting herbicides and SAH were already reported back into the 90s (Rey-Caballero et al., 2017), and now they are also spreading in other European countries (Kati et al., 2019). While it is demonstrated that both TSR and enhanced metabolism to ALS inhibiting herbicides can be found in a single plant, no direct evidences of responsible enzyme families have been provided (Rey-Caballero et al., 2017). For the first time, an imazamox hydroxyl metabolite was found in a single population from Spain, as the only direct evidence of enhanced metabolism to ALS inhibiting herbicides in this species (Rey-Caballero et al., 2017). Regarding resistance to SAH, only in two HR $P$. rhoeas populations from Spain the presence of enhanced metabolism, and malathion as 2,4-D synergist in whole plant studies, have been demonstrated as indirect evidence of P450-mediated degradation (Torra et al., 2017). The presence of the two hydroxy 2,4-D metabolites in these two populations was ascribed according to HPLC retention times (Torra et al., 2017). Finally, it has also been shown that resistance mechanisms to both ALS inhibiting herbicides and SAH can co-exist within a single plant from multiple HR $P$. rhoeas populations (Kati et al., 2019). On the other hand, remains to be investigated whether the detoxifying mechanisms in multiple HR populations with enhanced metabolism to SAH and ALS inhibiting herbicides are linked. For example, a characterization of the possible P450s involved in the degradation of both SoAs using different inhibitors would be of value, not only to demonstrate that P450s are able to degrade ALS inhibiting herbicides in P. rhoeas, but also to understand if common or different P450s can lead to cross and/or multiple resistance, respectively, to herbicides with these two SoAs.

The objectives of this research were to (1) study the presence of enhanced metabolism both to ALS inhibiting herbicides and SAH in HR $P$. rhoeas populations with different resistance profiles, (2) evaluate for the first time if P450 is involved in the detoxification of ALS inhibiting herbicides, and further confirm that is also involved in the detoxification process of 2,4-D, and (3) understand if there are potential P450 conferring cross-resistance to these two SoA in HR P. rhoeas. To meet these objectives, metabolism studies with imazamox and 2,4-D were carried in populations with different HR profiles: susceptible, putative with only TSR to ALS inhibiting herbicides, only with NTSR to SAH, and multiple HR to both SoA. Also, three different P450 inhibitors (malathion, aminotriazole and piperonyl butoxide) were used to compare inhibition patterns between imazamox and 2,4-D metabolism and metabolites present.

\section{Materials and methods}

\subsection{Plant material}

All the populations used in this research are already well characterized in different studies in terms of their resistance profiles (Rey-Caballero et al., 2016, 2017; Torra et al., 2017). One susceptible (S) population to ALS inhibiting herbicides and SAH was used. Four Spanish field-evolved HR populations with different resistance profiles were included (Table 1). From those four HR populations, three populations are multiple HR to ALS inhibiting herbicides and SAH (M-HR 1 to 3), while one population is only R to 2,4-D (SAH-R). Whereas in populations M-HR 1 to 3 several amino acid substitutions were found only in position Pro197, no alterations of the ALS gene were found in population SAH-R. From those, populations M-HR 2 and SAH-R showed enhanced rates of 2, 4-D metabolism, and malathion synergized with the herbicide in whole plant assays (Torra et al., 2017). Moreover, population M-HR 3 is the only HR $P$. rhoeas population where direct evidences of enhanced metabolism to ALS inhibiting herbicides have been found so far in previous studies (Rey-Caballero et al., 2017). Finally, one biotype only R to ALS inhibiting herbicides, with all plants homozygous for the amino acid substitution Pro197Ser was kindly provided by Corteva Agrisciences and included as putative resistant standard with only TSR. This population was obtained thanks to several runs of cross-pollination procedures between plants previously sequenced to possess only this substitution. Not all populations were included in every experiment.

Seeds were sown in aluminium trays with peat and placed in a growth chamber at $20 / 10{ }^{\circ} \mathrm{C}$ day/night, $16 \mathrm{~h}$ photoperiod under 850 $\mu \mathrm{mol}$ photosynthetic photon-flux density $\mathrm{m}^{-2} \mathrm{~s}^{-1}$. After 14 days, seedlings were transplanted in $7 \times 7 \times 7 \mathrm{~cm}$ plastic pots filled with soil:peat moss (1:1) mixture. Pots were placed in a greenhouse in University of Cordoba and were watered regularly and fertilized as required.

Two seedlings were sown per pot. When they reached the six leaf stage (a 5-6 cm rosette), plants were sprayed with either imazamox (Pulsar 40, imazamox 40\%, BASF) or 2,4-D (Esteron 60, 2,4-D ester 60\%, Dow AgroSciences), depending on the experiment, with a treatment chamber (SBS-060 De Vries Manufacturing, Hollandale, MN, United States) equipped with 8002 flat fans nozzle and delivering $200 \mathrm{~L} \mathrm{ha}^{-1}$ at 
Table 1

Resistance profile for ALS inhibiting herbicides and 2,4-D of the Papaver rhoeas populations used in the experiments.

\begin{tabular}{|c|c|c|c|c|c|c|c|}
\hline \multirow[t]{2}{*}{ Population } & \multirow[t]{2}{*}{ Code } & \multicolumn{3}{|l|}{ ALS } & \multicolumn{3}{|c|}{ 2,4-D } \\
\hline & & R.P. & TSR & Enhanced metabolism & R.P. & Enhanced metabolism & P450 \\
\hline Susceptible & $S$ & $S$ & none & none & $S$ & none & none \\
\hline TSR to ALS & ALS-R & $\mathrm{R}$ & Pro197Ser & unknown & $S$ & - & - \\
\hline $\mathrm{R}$ to $2,4-\mathrm{D}$ & SAH-R & $\mathrm{S}$ & none & unknown & $\mathrm{R}$ & yes & yes \\
\hline \multirow[t]{3}{*}{ Multiple HR to ALS and 2,4-D } & M-HR 1 & $\mathrm{R}$ & Pro197 & unknown & $\mathrm{R}$ & unknown & - \\
\hline & M-HR 2 & $\mathrm{R}$ & Pro197 & unknown & $\mathrm{R}$ & yes & yes \\
\hline & M-HR 3 & $\mathrm{R}$ & Pro197 & yes & $\mathrm{R}$ & unknown & - \\
\hline
\end{tabular}

${ }^{a}$ R.P.: resistance profile in whole plant dose-response experiments; population NTSR: susceptible to SU, very low resistance levels to other ALS inhibitors; Pro197Ser: homozygous for this amino acid substitution; Pro197: different amino acid substitution in this position.

$250 \mathrm{KPa}$.

\subsection{Imazamox metabolism studies}

The methodology followed was described by Rojano-Delgado et al. (2014). Application of imazamox was performed as described above with a dose of imazamox at $50 \mathrm{~g}$ ai ha ${ }^{-1}$ (field rate) as well as a 0 dose (control). Six plants treated with herbicide and the controls were cut 72 , 96 and $168 \mathrm{~h}$ after treatment (HAT). The samples were washed with 60 $\mathrm{mL}$ of distilled water to remove imazamox and soil residues on the leaf surface. Compared to previous studies with $P$. rhoeas (Rey-Caballero et al., 2017), longer evaluation times than 72 HAT were included to increase the feasibility of metabolism detection. They were stored at $-40{ }^{\circ} \mathrm{C}$ until to start the extraction.

Imazamox and metabolites were determined by the liquid chromatography-DAD (diode array detector analysis) at a measurement wavelength of $240 \mathrm{~nm}$. A Gold HPLC (High-performance liquid chromatography) System from Beckman Coulter (Fullerton, USA) equipped with a 26 System Gold Diode Array detector (wavelength range 190-600 nm) was used in this case. Liquid chromatography-DAD was performed by using two plants per sample (three repetitions) and five populations (S, SAH-R, M-HR 1 to 3). Population M-HR 3 was included as resistant standard population with imazamox enhanced metabolism (Rey-Caballero et al., 2017).

\subsection{2,4-D metabolism studies}

Metabolism studies for 2,4-D were performed according to the methods described by Torra et al. (2017), which are based on previous methodologies (Chkanikov et al., 1977; Hamburg et al., 2001). These methodologies were adapted and modified to identify and quantify the herbicide and its metabolites by a chromatographic method (HPLC), according to the retention times. Application of 2,4-D was applied at a dose of $600 \mathrm{~g}$ ai ha $^{-1}$ (field rate) as well as a 0 dose (control) on plants at the four to six leaf stage $(4-5 \mathrm{~cm})$. Six plants from each population and dose were harvested at 0,96 and $168 \mathrm{HAT}$ and stored at $-40{ }^{\circ} \mathrm{C}$ until use. Plants were separated into two parts: aerial part (leaves and shoots) and roots, each of which was rinsed using distilled water to remove unabsorbed herbicide. The frozen samples were washed with $60 \mathrm{~mL}$ of water to remove traces of 2,4-D and soil on the leaf surface, before the extraction.

Quantification of 2,4-D and its metabolites was based on the calibration curve of 2,4-D, which is the unique commercially available standard. The results were expressed as $\mu \mathrm{g}$ of the analyte $\mathrm{g}^{-1}$ of plant. HPLC was performed by using two plants per sample (three repetitions) for each population: S, M-HR 1 and M-HR 3. Resistant standard populations with 2,4-D enhanced metabolism were not included in this experiment because evaluation times to detect metabolites are well established (Torra et al., 2017) and they were already used in next experiments with P450 inhibitors.

\subsection{Herbicide metabolism studies with P450 inhibitors}

Metabolism studies for imazamox and 2,4-D were carried out as described in the previous sections using three different $\mathrm{P} 450$ inhibitors: malathion, aminotriazole (amitrole), and piperonyl butoxide (PBO). To understand the possible presence of enhanced metabolism in $P$. rhoeas depending on the resistance profile and mechanisms, different populations were included. At the four to six leaf stage $(4-5 \mathrm{~cm})$, plants were treated with either 0 or $2000 \mathrm{~g}$ a.i. ha ${ }^{-1}$ of malathion, either 0 or $2000 \mathrm{~g}$ a.i. ha ${ }^{-1}$ of PBO, or either 0 or $13.1 \mathrm{~g}$ a.i. ha ${ }^{-1}$ of amitrole dissolved in water. Rates were based on previous studies (Oliveira et al., 2018; Palma-Bautista et al., 2020; Torra et al., 2017). After approximately 120 min, either 2,4-D or imazamox were applied at $600 \mathrm{~g}$ a.i. ha ${ }^{-1}$ and $50 \mathrm{~g}$ a.i. $\mathrm{ha}^{-1}$, respectively, to all populations. Application settings were those previously described. Non-treated plants and treated only with P450 inhibitors were used as controls. Six plants from each population, herbicide, P450 inhibitor and dose were harvested at 0, 72 and 168 HAT and stored at $-40{ }^{\circ} \mathrm{C}$ until use.

Quantification of herbicides and their metabolites were carried out as previously described (Rojano-Delgado et al., 2014; Torra et al., 2017). Also, the results were expressed as $\mu \mathrm{g}$ of the analyte/g of plant. Liquid chromatography-DAD for imazamox and HPLC for 2,4-D were performed by using two plants per sample (three repetitions) for each population and treatment. Four populations were included for 2,4-D: S, ALS-R (only HR to ALS inhibitors), SAH-R (only HR to SAH) and M-HR 2 (multiple HR to both). For 2,4-D, the last two populations already served as resistant standards (Torra et al., 2017). For imazamox, these four populations together with population M-HR 3, as imazamox resistant standard, were included. Population M-HR 1 was not included because no metabolites were detected (see Results section 3.1). To corroborate the effect produced by the P450 inhibitors, a group of six plants were applied only with the inhibitors and studied.

\subsection{Statistical analysis}

One-way (population) Analysis of variance (ANOVA) were conducted with imazamox, 2,4-D and their metabolites quantities in each evaluation time and plant part. Two-way ANOVA (population and P450 inhibitor) were performed also with herbicides and metabolites quantities in each evaluation time and plant part. Data were transformed $(\operatorname{arcs}[\sqrt{ }(x+0.5)])$ as needed when normal assumptions were not met. Population means from each evaluation time were compared using a post-hoc Tukey's pairwise test (R Core Team, 2013), at $P=0.05$. Data were then back transformed for their presentation. 


\section{Results}

\subsection{Imazamox metabolism studies}

The imazamox time-related metabolic pattern was different between the $\mathrm{S}$ and all HR $P$. rhoeas populations at all evaluation times (Supplementary Appendix, Fig. S1). At the three sampling times, significantly more herbicide was detected in the $S$ population. At $72 \mathrm{HAT}$, the M-HR 1 population had significantly the lowest amount of herbicide in the aerial part of the plants, while at 96 and 168 HAT was the M-HR 3 population.

Imazamox was only detected in roots in the $S$ population at $72 \mathrm{HAT}$, while at 96 and 168 HAT the amount was significantly much higher compared to HR ones. The liquid chromatography-DAD revealed the presence of a hydroxy metabolite of imazamox (at 17-18 $\mathrm{min}$ in the chromatogram, Fig. 1) in the aerial part in one of the HR populations, MHR 3, at $72 \mathrm{HAT}$, in this and SAH-R (only R to SAH) populations at 96 HAT, and in both populations and also in the M-HR one, at 168 HAT (Supplementary Appendix, Fig. S1). The amount of the metabolite was much higher in aboveground part of the plants. In roots, it was not detected in any population at $72 \mathrm{HAT}$, only in M-HR 3 population at 96 HAT, and in M-HR 2 and 3 populations at 168 HAT.

Finally, the liquid chromatography-DAD also revealed the presence of a sugar conjugate metabolite of imazamox (at 15-16 min in the chromatogram, Fig. 1) in the aerial part in one of the HR populations at 96 HAT (M-HR 3), and in two populations, M-HR 2 and 3, at 168 HAT (Supplementary Appendix, Fig. S1), both multiple HR to ALS inhibitors and SAH. This metabolite and the hydroxyl one identified appeared to be mobile within $P$. rhoeas plants, since they were found both in shoots and, to a lesser amount, in roots.

\subsection{2,4-D metabolism studies}

Qualitative and quantitative differences were found between the S and multiple HR populations in the HPLC profile (Fig. 2). As previous studies (Torra et al., 2017), 2,4-D had a retention time on HPLC of around $17 \mathrm{~min}$. HR $P$. rhoeas populations produced two polar metabolites, with HPLC retention times of 8 and 9 min, respectively (Fig. 2). The two metabolites detected, M1 and M2, were putatively ascribed to 2,4-D hydroxylated metabolites, non-toxic 2,3-D and 2,5-D, respectively, according to retention times in the HPLC.

There were differences in the 2,4-D metabolic pattern between the $S$ and the two HR populations at 96 and 168 HAT (Supplementary Appendix, Table S1). At both sampling times, significantly more herbicide was detected in the aerial part and roots of the S plants. At 96 HAT, both SAH-resistant biotypes had significantly lower amount of herbicide than $S$ plants, the M-HR1 population significantly showing the lowest amount of herbicide in the aerial part or roots of the plants. No herbicide was detected at 96 HAT in roots of the M-HR 3 populations or at 168 HAT in the two multiple HR populations studied (aerial part and roots).

Two metabolites were detected in both multiple HR populations at 96 HAT in the aerial part of the plants, while only in population M-HR 3 the M1 metabolite was detected in roots. At 168 HAT, both metabolites were found in the R $P$. rhoeas populations in the aerial parts. At this sampling time, M1 metabolite was found in higher amounts in M-HR 3 compared to M-HR 1 population, while the M2 metabolite was only detected in the M-HR 3 population (Supplementary Appendix, Table S1). Finally, the two 2,4-D metabolites found were also mobile within $P$. rhoeas plants, since they were found both in shoots and, to a lesser amount, in roots.

\subsection{Herbicide metabolism studies with $P 450$ inhibitors}

At both sampling times, significantly more imazamox was detected in the S and ALS-R (only R to ALS inhibitors) populations in the aerial parts or roots (Table S3), either without previous application of a P450 inhibitor or any of the three inhibitors tested (Fig. 3, up). In these two populations no imazamox metabolites were detected (Table 2).

Without the previous treatment of P450 inhibitors, the imazamox hydroxyl was only detected in the aerial parts of M-HR 3 population at 72 HAT (Table 2). At 168 HAT, it was detected in the aerial parts of SAH$\mathrm{R}$ (only R to SAH), M-HR 2 and 3 populations (multiple HR to ALS inhibitors and SAH) (Table S3), and in the roots of M-HR 2 and 3 populations. The imazamox sugar conjugate was only detected at 168 HAT, in the aboveground parts of M-HR 2 and 3 populations, and in roots of

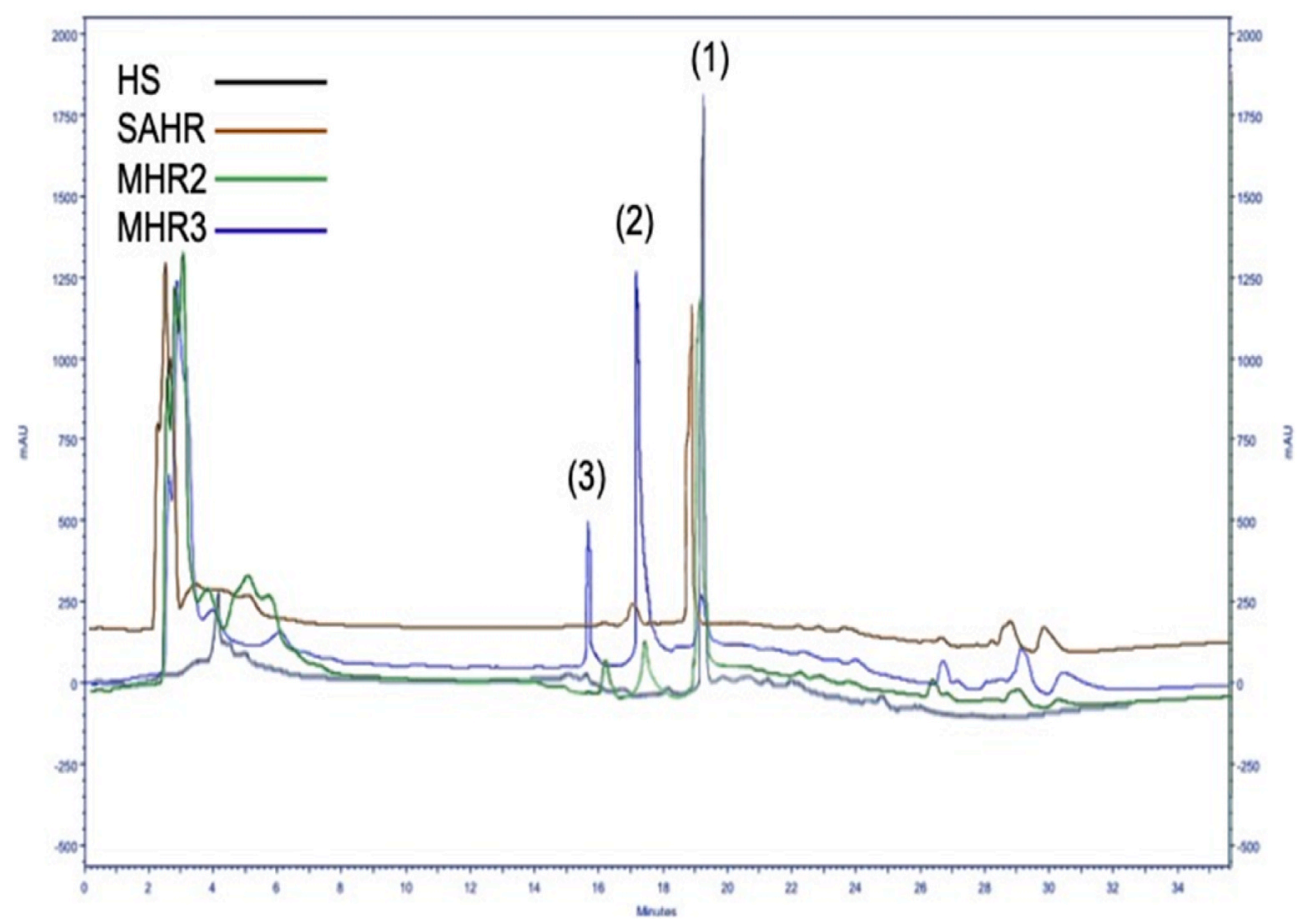

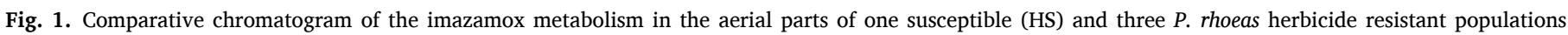

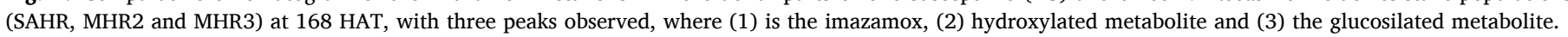




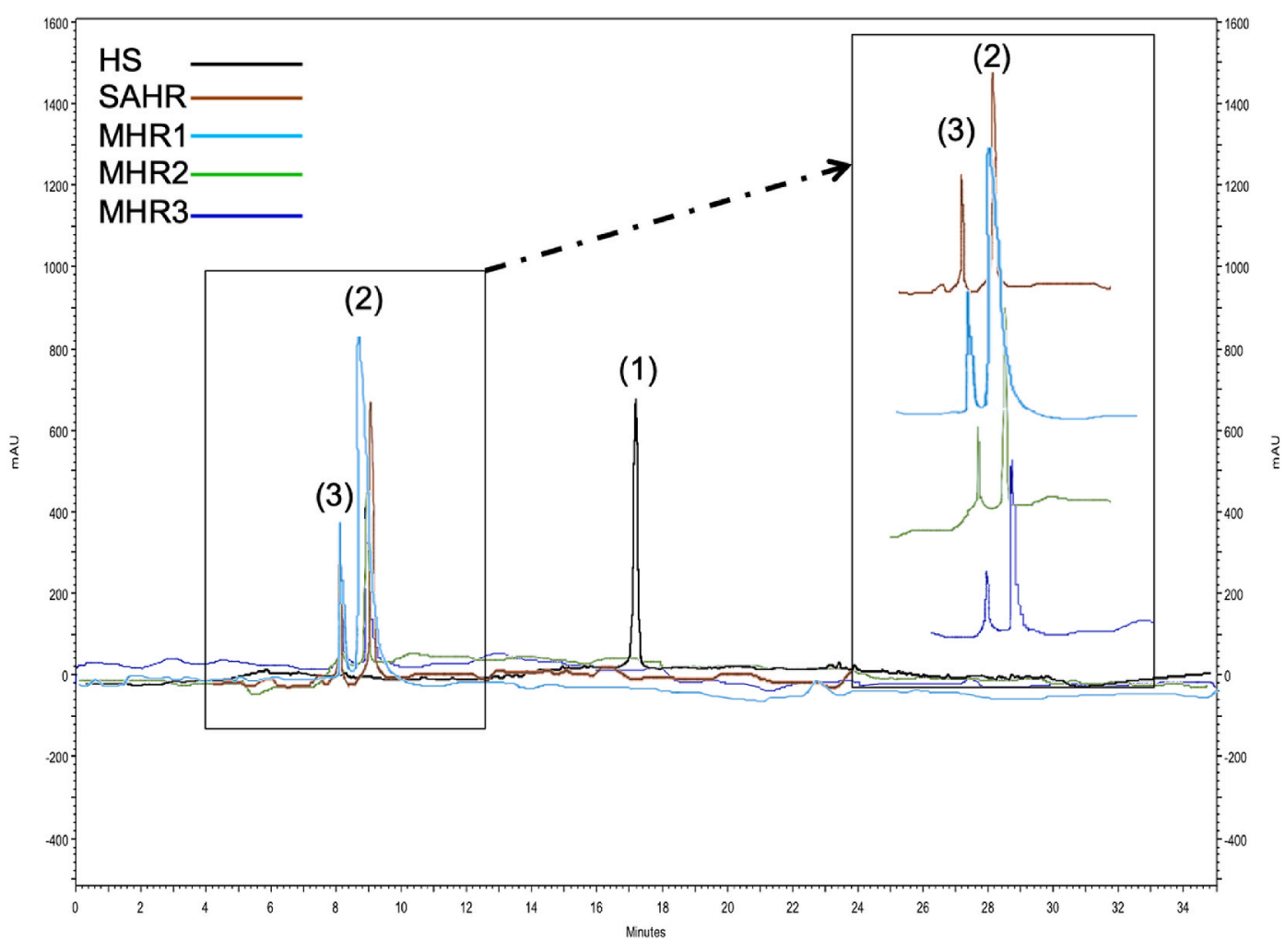

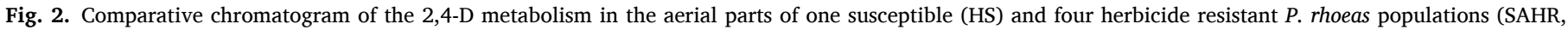
MHR1 to 3) at 168 HAT with three peaks detected, where (1) is the 2,4-D, (2) the MET1 and (3) the MET 2.

only the M-HR 3 population (Table 2).

When P450s inhibitors were applied $2 \mathrm{~h}$ before the imazamox, either malathion, PBO or amitrole, no imazamox metabolites were detected (data not shown) in the populations where they were found when the herbicide was applied alone (Fig. 4). Only imazamox was detected both in the aerial parts or roots (Table 2).

The application of the three $\mathrm{P} 450$ inhibitors alone produced no visual injury in all populations (Fig. S2). More imazamox was present in the aerial parts compared to roots at 72 HAT in all populations regardless of the treatment (Fig. 3). On the other hand, at 168 HAT, more imazamox was found in roots of S and ALS-R when malathion or amitrole were used. This pattern was not observed in the populations with imazamox enhanced metabolism (Fig. 3).

Regarding 2,4-D, significantly more parental herbicide was detected in the S and ALS-R (only R to ALS inhibitors) populations at both sampling times in the aerial parts or roots (Table S4), either without previous application of a P450 inhibitor or any of the three inhibitors tested (Fig. 5). In these two populations no 2,4-D metabolites were detected (Table 2).

Without the previous treatment of P450 inhibitors, the two 2,4-D metabolites were detected in the aerial parts of SAH-R (only R to $\mathrm{SAH}$ ) and M-HR 2 (multiple HR) populations at $72 \mathrm{HAT}$, but not in roots (Table 2). At 168 HAT, M1 and M2 metabolites were detected in the aerial parts of these two populations, while only M1 metabolite was detected in roots. No 2,4-D was found in these populations in the second sampling time (Table 2).

When a P450 inhibitor was applied $2 \mathrm{~h}$ before the herbicide, either malathion, PBO or amitrole, no 2,4-D metabolites were detected in the populations where they were found when the herbicide was applied alone (Fig. 6). Only 2,4-D was detected both in the aerial parts or roots (Fig. 5). When PBO was used, more herbicide was detected in roots of all populations, compared to malathion and amitrole, at both sampling times. With malathion and amitrole most of the 2,4-D remained in the aerial part of the plants (Fig. 5).
The overall effects of the three P450 inhibitors used in the metabolism of 2,4-D and imazamox are summarized in Table 3. When any of the three P450 inhibitors used (malathion, PBO or amitrole), was applied $2 \mathrm{~h}$ before the herbicides, no metabolites were detected, both for imazamox or 2,4-D, regardless of the population resistance profile. Therefore, enhanced metabolism was inhibited both in SAH-R (only R to $\mathrm{SAH}$ ) and M-HR populations (multiple HR to ALS inhibitors and SAH) and both 2,4-D and imazamox synergized with the three inhibitors.

\section{Discussion}

The results from the experiments presented in this research clearly show that the presence of enhanced metabolism in HR $P$. rhoeas is the NTSR resistance mechanism in different populations from Spain, both to ALS inhibiting herbicides and SAH. Regarding imazamox metabolism experiments, the presence of enhanced degradation has been confirmed in two more populations, M-HR 2 (multiple HR to ALS inhibiting herbicides and SAH), and SAH-R (only R to SAH), besides the standard multiple HR population M-HR 3 (Supplementary Appendix, Fig. S1). These populations were already analysed in a previous study with 72 HAT as longest evaluation time, but only in the latest population the hydroxyl metabolite was detected (Rey-Caballero et al., 2017). In this study, evaluation times were extended up to $168 \mathrm{HAT}$, allowing the detection of imazamox metabolites in more populations. Regarding 2, 4-D metabolism experiments, the presence of enhanced degradation of this SAH has also been confirmed in the two populations studied, M-HR 1 and M-HR 3 (Supplementary Appendix, Table S1), both multiple HR to ALS inhibiting herbicides and 2,4-D, as found in previous studies in another two populations from Spain (Torra et al., 2017).

In the second run of studies, the pre-treatment of HR P. rhoeas plants with different P450 inhibitors synergized both with imazamox and 2,4-D in the metabolism experiments using one of these two herbicides (Figs. 4 and 6, Table 3). Therefore, for the first time, it is demonstrated that P450s are involved in the degradation of ALS inhibiting herbicides in HR 

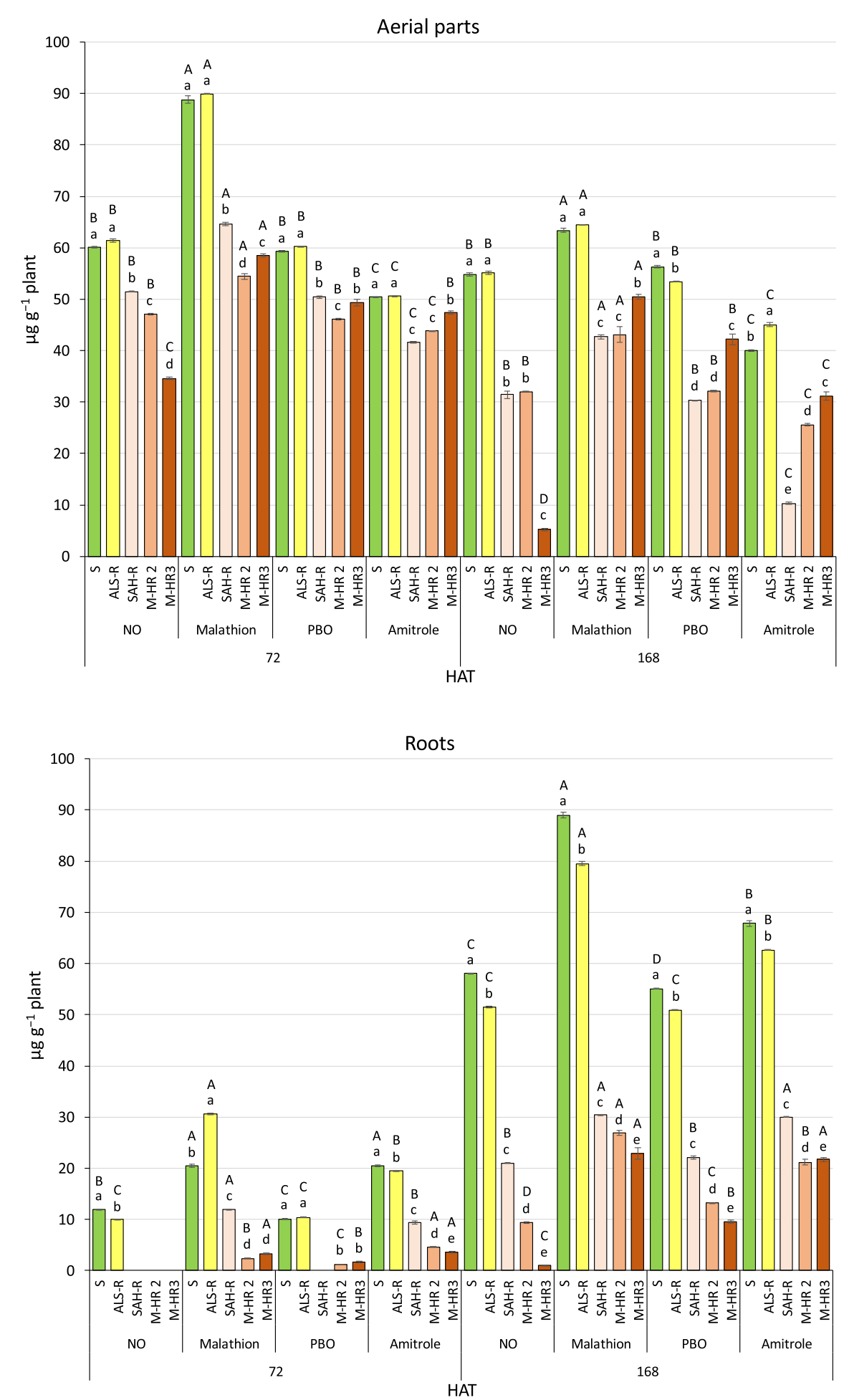

Fig. 3. Amount of imazamox ( $\mu \mathrm{g} \mathrm{g}^{-1}$ plant, $\mathrm{n}=3$ replicates, mean $\pm \mathrm{SE}$ ) detected by liquid chromatography-DAD in extracts of plants (aerial parts, up; roots, bottom) from one susceptible (S) and four resistant (ALS-R, SAH-R, M-HR 2 and M-HR 3) corn poppy (Papaver rhoeas) populations, without (NO) or with previous applications of three different cytochrome $\mathrm{P} 450$ inhibitors (malathion, piperonyl butoxide as PBO, amitrole), evaluated at 72 and $168 \mathrm{~h}$ after treatment (HAT). Means within an evaluation time and inhibitor treatment with the same letter are not significantly different at the $5 \%$ level as determined by the Tukey test; means for the same population and evaluation time with the same capital letter are not significantly different at the $5 \%$ level as determined by the Tukey test.
P. rhoeas. The role of P450 in NTSR to ALS inhibiting herbicides has been recently demonstrated in few broadleaf weed species (Liu et al., 2018; Shergill et al., 2018; Yang et al., 2018). Regarding 2,4-D, these results further confirm the involvement of P450s in the metabolism of SAH in HR $P$. rhoeas. These results are consistent with previous studies where malathion was shown to synergize 2,4-D action on the HR populations SAH-R (only R to SAH) and M-HR 2 (multiple HR to ALS inhibitors and $\mathrm{SAH}$ ) in greenhouse experiments (Torra et al., 2017). The effects of this P450 inhibitor on the whole plants in these two populations correlated well with its ability to inhibit their herbicide metabolism in this research.

The most remarkable result from the metabolism experiments with P450 inhibitors, was that all of them, malathion, PBO and amitrole, synergized with either imazamox or 2,4-D, and no metabolites were detected in the two HR P. rhoeas populations that showed enhanced degradation rates without inhibitors (Table 3, Figs. 4 and 6). Based on the common patterns of inhibition of herbicide metabolism by P450s in these metabolism experiments, it can be suggested that at least one 
Table 2

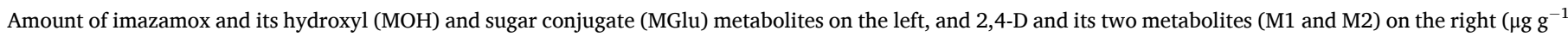

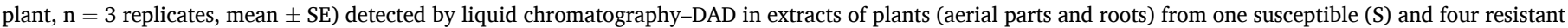

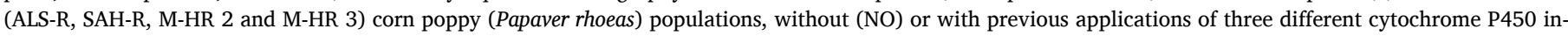

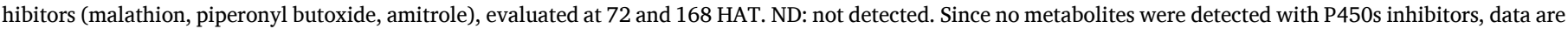
not shown.

\begin{tabular}{|c|c|c|c|c|c|c|c|c|c|}
\hline \multirow[t]{3}{*}{ HAT } & \multirow[t]{3}{*}{ Population } & \multicolumn{4}{|l|}{ Imazamox } & \multicolumn{4}{|l|}{$2,4-\mathrm{D}$} \\
\hline & & \multicolumn{2}{|l|}{ Aerial part ${ }^{\mathrm{a}}$} & \multicolumn{2}{|l|}{ Roots $^{\mathrm{a}}$} & \multicolumn{2}{|l|}{ Aerial part ${ }^{\mathrm{a}}$} & \multicolumn{2}{|l|}{ Roots $^{\mathrm{a}}$} \\
\hline & & $\mathrm{MOH}$ & MGlu & $\mathrm{MOH}$ & MGlu & M1 & M2 & M1 & M2 \\
\hline \multirow[t]{5}{*}{72} & $\mathrm{~S}$ & ND & ND & ND & ND & ND & ND & ND & ND \\
\hline & ALS-R & ND & ND & ND & ND & ND & ND & ND & ND \\
\hline & SAH-R & ND & ND & ND & ND & $4.4 \pm 0.2 \mathrm{a}$ & $0.7 \pm 0.2 \mathrm{a}$ & ND & ND \\
\hline & M-HR 2 & ND & ND & ND & ND & $1.2 \pm 0.0 \mathrm{~b}$ & $0.1 \pm 0.0 \mathrm{~b}$ & ND & ND \\
\hline & M-HR3 & $10.9 \pm 0.6$ & ND & ND & ND & - & - & - & - \\
\hline \multirow[t]{5}{*}{168} & $\mathrm{~S}$ & ND & ND & ND & ND & ND & ND & ND & ND \\
\hline & ALS-R & ND & ND & ND & ND & ND & ND & ND & ND \\
\hline & SAH-R & $1.2 \pm 0.1 \mathrm{c}$ & ND & ND & ND & $8.3 \pm 0.2 \mathrm{a}^{*}$ & $2.7 \pm 0.2 b^{*}$ & $0.2 \pm 0.0$ & ND \\
\hline & M-HR 2 & $2.8 \pm 0.2 \mathrm{~b}$ & $0.8 \pm 0.0 \mathrm{~b}$ & $1.0 \pm 0.0 \mathrm{~b}$ & ND & $8.1 \pm 0.1 \mathrm{a}^{*}$ & $4.4 \pm 0.1 \mathrm{a}^{*}$ & $0.1 \pm 0.0$ & ND \\
\hline & M-HR3 & $24.5 \pm 0.3 \mathrm{a}^{*}$ & $10.6 \pm 0.1 \mathrm{a}$ & $3.9 \pm 0.1 \mathrm{a}$ & $5.0 \pm 0.1$ & - & - & - & - \\
\hline
\end{tabular}

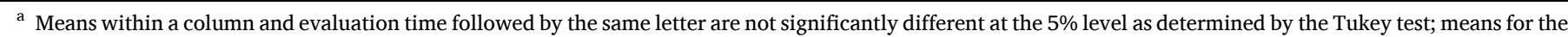
same population, plant part (aerial or roots) and compound with an asterisk (*) are significantly different at the $5 \%$ level as determined by the Tukey test.

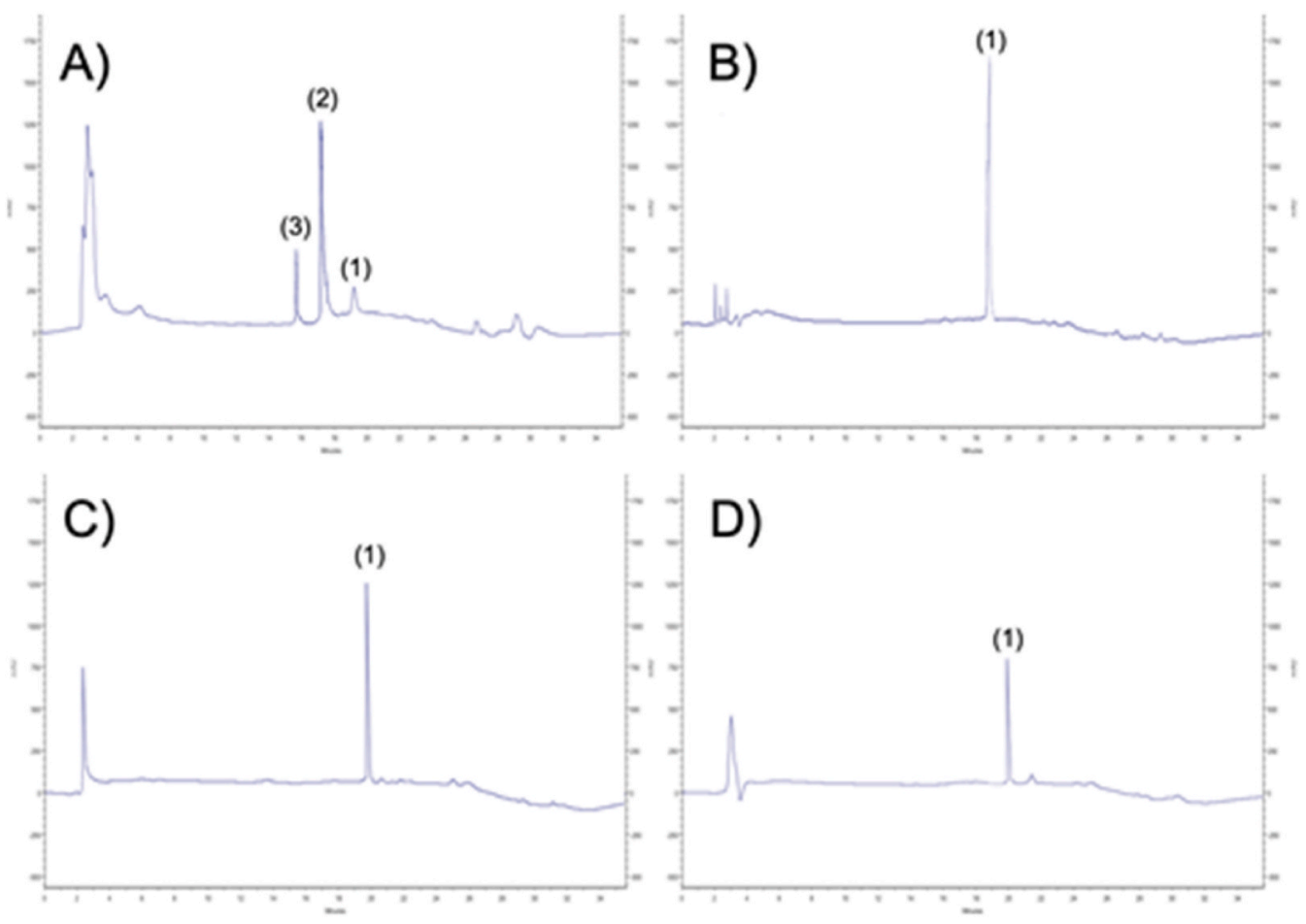

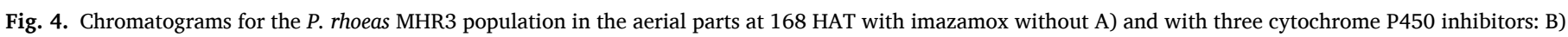
malathion, C) PBO and D) amitrol. Where (1) is imazamox, (2) hydroxylated metabolite and (3) the glycosylated metabolite.

metabolic system, probably involving one P450, contribute to enhanced herbicide detoxification in the populations M-HR 2 (multiple HR to ALS inhibitors and SAH) and SAH-R (only R to SAH) to both ALS inhibiting herbicides (imazamox) and SAH (2,4-D). Another less feasible hypothesis is that different P450s could be involved in the degradation of these two SoAs, which would synergize with the three inhibitors used. The presence of metabolic-based herbicide resistance in $P$. rhoeas suggests that multiple herbicide resistance, if at least one common P450 is responsible, could partly be due to cross-resistance. This study provides the second evidence worldwide that $\mathrm{P} 450$ s could provide crossresistance to ALS inhibiting herbicides (imazamox) and 2,4-D in a broadleaf weed species (Shergill et al., 2018). It has to be deciphered if other mechanisms could contribute to 2,4-D resistance since impaired transport has also been described previously in populations M-HR 2 and SAH-R (Rey-Caballero et al., 2016). It is interesting to stress that amitrole apparently increased imazamox mobility to roots (168 HAT), while this effect was not observed for 2,4-D, or it was not so strong. There is not literature about potential secondary effects that P450 inhibitors can have on plants, besides the targeted inhibition, i.e. on herbicide transport.

The multiple HR populations studied here (M-HR 1 to 3) are known to possess several amino acid substitutions in the position Pro197 (Rey-Caballero et al., 2017). On the other hand, the population SAH-R did not show in alteration of the ALS gene, though it showed low resistance levels to imazamox (resistant factor of 6) and almost full susceptibility to florasulam and tribenuron (resistant factors of 2) in 


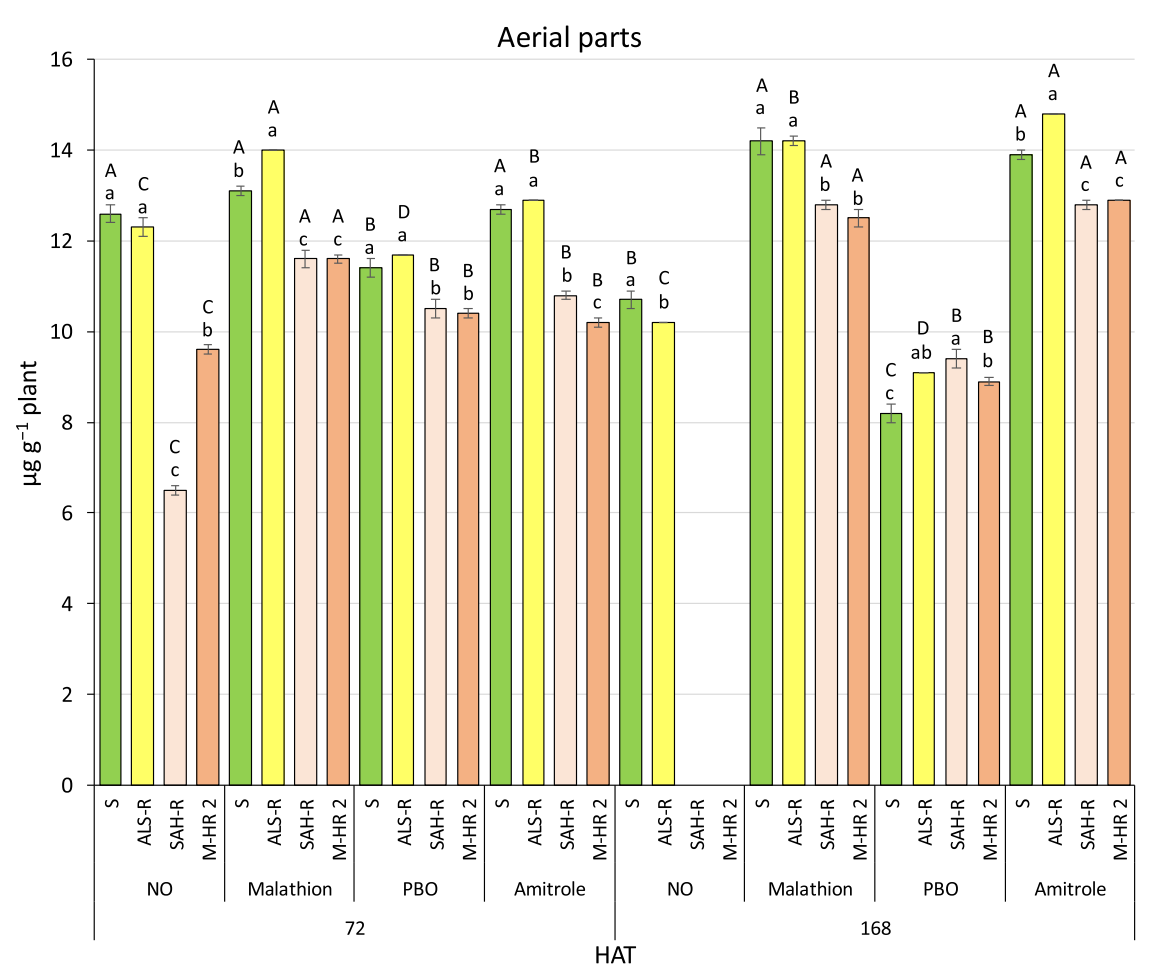

Roots

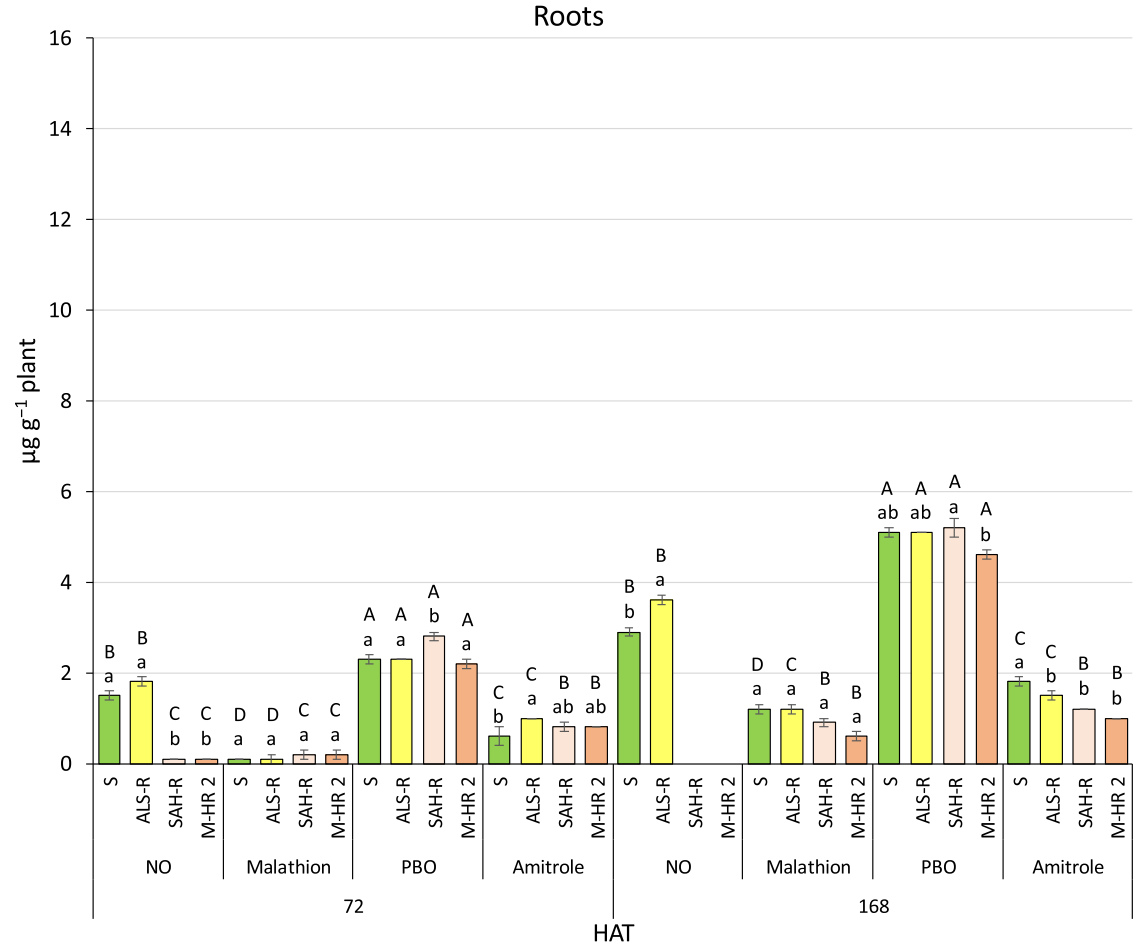

Fig. 5. Amount of 2,4-D ( $\mu \mathrm{g} \mathrm{g}^{-1}$ plant, $\mathrm{n}=3$ replicates, mean $\pm \mathrm{SE}$ ) detected by liquid chromatography-DAD in extracts of plants (aerial parts, up; roots, bottom) from one susceptible (S) and three resistant (ALS-R, SAH-R and M-HR 2) corn poppy (Papaver rhoeas) populations, without (NO) or with previous applications of three different cytochrome P450 inhibitors (malathion, piperonyl butoxide as PBO, amitrole), evaluated at 72 and $168 \mathrm{~h}$ after treatment (HAT). Means within an evaluation time and inhibitor treatment with the same letter are not significantly different at the $5 \%$ level as determined by the Tukey test; means for the same population and evaluation time with the same capital letter are not significantly different at the $5 \%$ level as determined by the Tukey test. dose-response experiments (Rey-Caballero et al., 2107). Therefore, this population, characterized as $\mathrm{R}$ to SAH, points out that only NTSR mechanisms by means of P450-mediated metabolism can confer cross-resistance at least to non-sulfonylurea ALS inhibiting herbicides. In multiple HR $P$. rhoeas plants, both TSR and enhanced metabolism might contribute to resistance to ALS inhibiting herbicides, since it is known that a single plant from population M-HR 3 can carry both mechanisms (Rey-Caballero et al., 2017). On the other hand, in the ALS-R population (only R to ALS inhibitors), homozygous for the Pro197Ser substitution, only TSR would contribute the resistance to this SoA since no evidences of enhanced metabolism were found.

Two metabolites were found in the imazamox metabolism experiments by HPLC, identified as the hydroxyl and sugar conjugate thanks to the followed methodology (Rojano-Delgado et al., 2014). It is the first time that an imazamox sugar conjugate is found in the HR P. rhoeas to ALS inhibiting herbicides. The formation of this metabolite might involve a glucosyl transferase enzyme (GT), which catalyses a glucose conjugation and has been postulated as an enzyme implied in the 


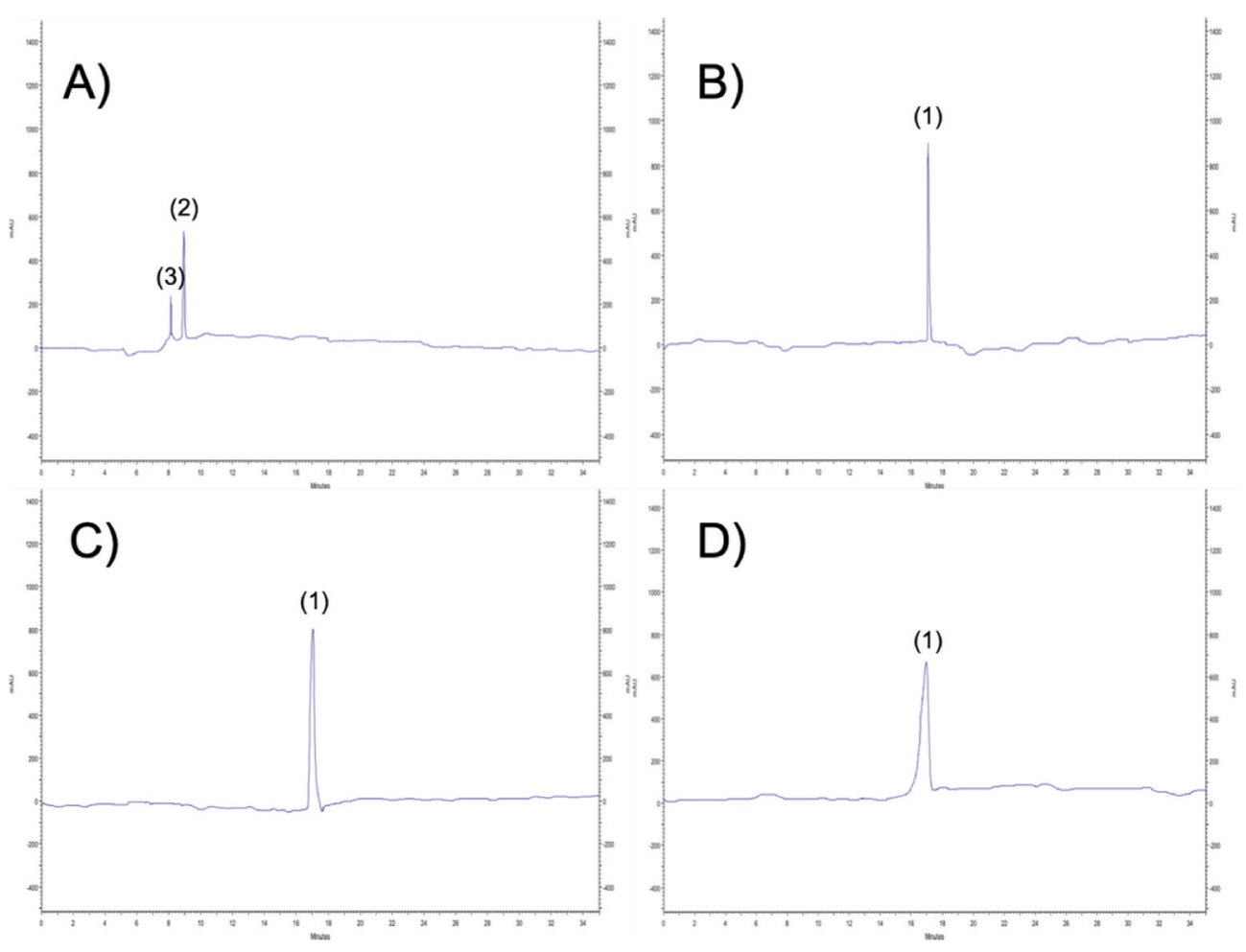

Fig. 6. Chromatograms for the P. rhoeas population MHR2 in the aerial parts at 168 HAT with 2,4-D without A) and with P450 inhibitors: B) malathion, C) PBO and D) amitrol. Where (1) is 2,4-D, (2) the MET1 and (3) the MET 2.

Table 3

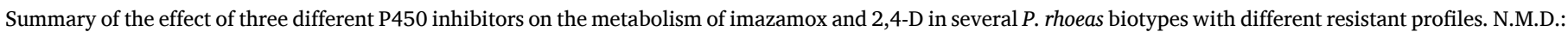
no metabolites detected, (also without inhibitors). Inhibited: metabolism was inhibited, while metabolites were detected without inhibitors.

\begin{tabular}{|c|c|c|c|c|c|c|}
\hline \multirow[t]{2}{*}{ Population } & \multicolumn{2}{|l|}{ Malathion } & \multicolumn{2}{|l|}{ PBO } & \multicolumn{2}{|l|}{ Amitrole } \\
\hline & Imazamox & $2,4-\mathrm{D}$ & Imazamox & 2,4-D & Imazamox & $2,4-\mathrm{D}$ \\
\hline$S$ & N.M.D. & N.M.D. & N.M.D. & N.M.D. & N.M.D. & N.M.D. \\
\hline ALS-R & N.M.D. & N.M.D. & N.M.D. & N.M.D. & N.M.D. & N.M.D. \\
\hline SAH-R & inhibited & Inhibited & Inhibited & Inhibited & Inhibited & Inhibited \\
\hline M-HR 2 & inhibited & inhibited & inhibited & inhibited & inhibited & inhibited \\
\hline M-HR 3 & inhibited & - & inhibited & - & inhibited & - \\
\hline
\end{tabular}

enhanced metabolism observed in other resistant cases (Yu and Powles, 2014b). A wheat-like P450 metabolism of chlorsulfuron was reported in L. rigidum in which chlorsulfuron was hydroxylated at the phenyl ring, followed by glucose conjugation (Yu and Powles, 2014b). This hypothesis could not indirectly be confirmed in this research, since to best of our knowledge, there are not known GT inhibitors to be used. The fact that the sugar conjugate was not detected with P450 inhibitors pre-treatment also suggests the hypothesis that imazamox degradation is a two-step process, involving P450s in Phase I and GT in phase II. Since imazamox metabolites were found both in shoots and, to a lesser amount, in roots, herbicide translocation and later degradation in roots cannot be ruled out.

Different 2,4-D degradation routes are known in plants including side-chain degradation, side-chain lengthening, ring hydroxylation, conjugation, and ring cleavage (Riar et al., 2011). It seems that the primary 2,4-D metabolic pathway in grasses is ester hydrolysis mediated by P450s (Hamburg et al., 2001). Conversely, dicotyledonous species detoxify SAH in a different metabolic route after ester hydrolysis, mainly by means of ring hydroxylation, also involving P450s (Hatzios et al., 2005). It is likely that the two ascribed 2,4-D hydroxy metabolites were phase I products in reactions catalysed by P450s, that is, ring or methyl hydroxylates. Full 2,4-D metabolite identification in HR P. rhoeas is still pending and would further confirm these results and unravel potential degradation routes in this species and other enzyme families involved. Different rates of herbicide metabolism were found between multiple HR $P$. rhoeas populations and also the SAH-R population, both for imazamox and 2,4-D. This putative herbicide degradation primarily $\mathrm{P} 450-$ based could be due to single nucleotide polymorphism, gene amplification or regulatory changes (Dimaanoa and Iwakami, 2020). Differences in gene copy numbers or regulatory changes in the P450s across populations might explain these different metabolism levels. Also, it is feasible that this metabolic system based on P450 is under polygenic control, and that more or less genes could be accumulated depending on the population. The polygenic nature of cytochrome P450 metabolism-based herbicide resistance has already been demonstrated (Busi et al., 2011).

\section{Conclusions}

Enhanced metabolism both to ALS inhibiting herbicides (imazamox) and SAH (2,4-D) was confirmed in HR P. rhoeas populations, and strong proofs were provided that is primarily P450-based in both SoAs. This study provided the first direct evidences that imazamox metabolism is mediated by $\mathrm{P} 450$ and confirmed previous studies that enhanced metabolism to SAH involved this enzyme family too. Also, data clearly suggested that a common metabolic system involving P450s is 
responsible of degrading both SoAs in HR $P$. rhoeas. The implications in terms of herbicide resistance management in this species are very important, because selection pressure with either 2,4-D or imidazolinone ALS inhibiting herbicides can select not only for resistance to one of them, but it can also confer cross-resistance between them. Likewise, since SAH and ALS inhibiting herbicides can select for the same NTSR mechanism, putative enhanced metabolism by P450s, their application together, either tank mixed or formulated, are not recommended, or should include other SoAs that are metabolized in different ways to decrease the selection pressure on the same metabolic route. Future research should decipher the identity of genes involved in enhanced metabolism in HR P. rhoeas, particularly P450s, aiding in the prediction of cross-resistance patterns across different herbicide chemistries. Also, cross-resistance to other SAH chemistries and mechanisms involved, or the probability of resistance evolution to other SoAs in multiple HR $P$. rhoeas should be investigated, to understand the threat that P450based herbicide resistance poses for the management of this weed species.

\section{Author contributions}

Conceptualization, J.T., A.M.R.-D., M.S., and R.D.P.; methodology, J. T., A.M.R.-D., J.M., and R.D.P.; software, J.T., A.M.R.-D., J.M., M.S., and R.D.P.; validation, J.T., A.M.R.-D., and R.D.P.; formal analysis, J.T. and A.M.R.-D.; investigation, J.T., A.M.R.-D., J.M., M.S., and R.D.P.; resources, J.T., M.S., and R.D.P.; data curation, J.T. and A.M.R.-D.; writing-original draft preparation, J.T., A.M.R.-D., and R.D.P.; writing-review and editing, J.T., A.M.R.-D., J.M., M.S., and R.D.P.; visualization, J.T., A.M.R.-D., J.M., M.S., and R.D.P.; supervision, J.T., M.S., and R.D.P.; project administration, J.T. and M.S.; funding acquisition, J.T. and M.S. All authors have read and agreed to the published version of the manuscript.

\section{Declaration of competing interest}

The authors declare that they have no known competing financial interests or personal relationships that could have appeared to influence the work reported in this paper.

\section{Acknowledgements}

The authors gratefully acknowledge Corteva Agrisciences for funding the experiments and also the support from the Cathedra University of Lleida-Corteva Agrisciences. The research undertaken at the University of Lleida-Agrotecnio has been supported by the Spanish Government, through project AGL 2017-83325-C4-2-R (AEI/FEDER/UE). Joel Torra acknowledges support from the Spanish Ministry of Science, Innovation and Universities (grant Ramon y Cajal RYC 2018-023866-I).

\section{Appendix A. Supplementary data}

Supplementary data to this article can be found online at https://doi. org/10.1016/j.plaphy.2021.01.007.

\section{References}

Busi, R., Vila-Aiub, M.M., Powles, S.B., 2011. Genetic control of a cytochrome P450 metabolism-based herbicide resistance mechanism in. Lolium rigidum Heredity 106, 817-824.

Busi, R., Goggin, D.E., Heap, I.M., Horak, M.J., Jugulam, M., Masters, R.A., Napier, R.M., Riar, D.S., Satchivi, N.M., Torra, J., Westra, P., Wright, T.R., 2018. Weed resistance to synthetic auxin herbicides. Pest Manag. Sci. 74, 2265-2276.

Chkanikov, D.I., Makeyev, A.M., Pavlova, N.N., Grygoryeva, L.V., Dubovoi, V.P., Klimov, O.V., 1977. Variety of 2,4-D metabolic pathways in plants; its significance in developing analytical methods for herbicides residues. Arch. Environ. Contam. Toxicol. 5, 97-103.

Délye, C., Jasieniuk, M., Le Corre, V., 2013. Deciphering the evolution of herbicide resistance in weeds. Trends Genet. 29, 649-658.
Dimaanoa, N.G., Iwakami, S., 2020. Cytochrome P450-mediated herbicide metabolism in plants: current understanding and prospects. Pest Manag. Sci. https://doi.org/ 10.1002/ps.6040.

Figueiredo, M.R., Leibhart, L.J., Reicher, Z.J., Tranel, P.J., Nissen, S.J., Westra, P., Bernards, M.L., Kruger, G.R., Gaines, T.A., Jugulam, M., 2018. Metabolism of 2,4 dichlorophenoxyacetic acid contributes to resistance in a common waterhemp (Amaranthus tuberculatus) population. Pest Manag. Sci. 74, 2356-2362.

Frear, D.S., Swanson, H.R., Tanaka, F.S., 1969. N-Demethylation of substituted 3(phenyl)-1-methylureas - isolation and characterization of a microsomal mixed function oxidase from cotton. Phytochemistry 8, 2157-2169.

Gaines, T.A., Duke, S.O., Morran, S., Rigon, C.A.G., Tranel, P.J., Küpper, A., Dayan, F.E., 2020. Mechanisms of evolved herbicide resistance. J. Biol. Chem. 295, 10307-10330.

Hall, L.M., Moss, S.R., Powles, S.B., 1995. Mechanism of resistance to chlorotoluron in two biotypes of the grass weed Alopecurus myosuroides. Pestic. Biochem. Physiol. 53, 180-192.

Hamburg, A., Puvanesarajah, V., Burnett, T.J., Barnekow, D.E., Premkumar, N.D., Smith, G.A., 2001. Comparative degradation of [14C]-2,4-Dichlorophenoxyacetic acid in wheat and potato after Foliar application and in wheat, Radish, lettuce, and apple after soil application. J. Agric. Food Chem. 49, 146-155.

Hatzios, K., Hock, B., Elstner, E.F., 2005. Metabolism and elimination of toxicants. In: Hock, B., Elstner, E.F. (Eds.), Plant Toxicology. CRC Press, Boca Raton, FL, pp. $469-518$.

Hyde, R.J., Hallahan, D.L., Bowyer, J.R., 1996. Chlorotoluron metabolism in leaves of resistant and susceptible biotypes of the grass weed Alopecurus myosuroides. Pestic. Sci. 47, 185-190.

Jugulam, M., Shyam, C., 2019. Non-target-site resistance to herbicides: recent developments. Plants 8, 417, 2019.

Kati, V., Scarabel, L., Thiery-Lanfranchi, D., Kioleoglou, V., Liberopoulou, S., Délye, C., 2019. Multiple resistance of Papaver rhoeas L. to 2,4-D and acetolactate synthase inhibitors in four European countries. Weed Res. 59, 367-376.

Kemp, M.S., Caseley, J.C., 1987. Synergistic effects of 1-aminobenzotriazole on the phytotoxicity of chlorotoluron and isoproturon in a resistant population of blackgrass (Aleperurus myosuroides). In: 1987 British Crop Protection Conference-Weeds. BCPC Publications, Surrey, pp. 895-899.

Liu, W., Bai, S., Zhao, N., Jia, S., Li, W., Zhang, L., Wang, J., 2018. Non-target site-based resistance to tribenuron-methyl and essential involved genes in Myosoton aquaticum (L.). BMC Plant Biol. 18, 225.

Ma, R., Kaundun, S.S., Tranel, P.J., Riggins, C.W., McGinness, D.L., Hager, A.G., Hawkes, T.R., McIndoe, E., Riechers, D.E., 2013. Distinct detoxification mechanisms confer resistance to mesotrione and atrazine in a population of waterhemp (Amaranthus tuberculatus). Plant Physiol. 163, 363-377.

Oliveira, M.C., Gaines, T.A., Dayan, F.E., Patterson, E.L., Jhala, A.J., Knezevic, S.Z., 2018. Reversing resistance to tembotrione in an Amaranthus tuberculatus (var. rudis) population from Nebraska, USA with cytochrome P450 inhibitors. Pest Manag. Sci. 74, 2296-2305.

Palma-Bautista, C., Rojano-Delgado, A.M., Dellaferrera, I., Rosario, J.M., Vigna, M.R., Torra, J., de Prado, R., 2020. Resistance mechanisms to 2,4-D in six different dicotyledonous weeds around the world. Agron 10, 566.

Preston, C., Tardif, F.J., Christopher, J.T., Powles, S.B., 1996. Multiple resistance to dissimilar herbicide chemistries in a biotype of Lolium rigidumDue to enhanced activity of several herbicide degrading enzymes. Pestic. Biochem. Physiol. 54, $123-134$.

Rey-Caballero, J., Menéndez, J., Osuna, M.D., Salas, M., Torra, J., 2017. Target-site and non-target-site resistance mechanisms to ALS inhibiting herbicides in Papaver rhoeas. Pestic. Biochem. Physiol. 138, 57-65.

Rey-Caballero, J., Menéndez, J., Giné-Bordonaba, J., Salas, M., Alcántara, R., Torra, J., 2016. Unravelling the resistance mechanisms to 2,4-D (2,4-dichlorophenoxyacetic acid) in corn poppy (Papaver rhoeas). Pestic. Biochem. Physiol. 133, 67-72.

Riar, D.S., Burke, I.C., Yenish, J.P., Bell, J., Gill, K., 2011. Inheritance and physiological basis for 2,4-D resistance in prickly lettuce (Lactuca serriola L.). J. Agric. Food Chem. 59, 9417-9423.

Rigon, C.A.G., Gaines, T.A., Anita, Küpper, Dayan, F.E., 2020. Metabolism-based herbicide resistance, the major threat among the non-target site resistance mechanisms. Outlooks Pest Manag. 31, 162-16.

Rojano-Delgado, A.M., Priego-Capote, F., de Prado, R., Luque de Castro, M.D., 2014 Ultrasound-assisted extraction with LC-TOF/MS identification and LC-UV determination of imazamox and its metabolites in leaves of wheat plants. Phytochem. Anal. 25, 357-363.

Shergill, L.S., Bish, M.D., Jugulam, M., Bradley, K.W., 2018. Molecular and physiological characterization of six-way resistance in an Amaranthus tuberculatus var. rudis biotype from Missouri. Pest Manag. Sci. 74, 2688-2698.

Siminszky, B., 2006. Plant cytochrome P450-mediated herbicide metabolism. Phytochem. Rev. 5, 445-458.

Singh, S., Kirkwood, R.C., Marshall, G., 1998. Effect of ABT on the activity and rate of degradation of isoproturon in susceptible and resistant biotypes of Phalaris minor and in wheat. Pestic. Sci. 53, 123-132.

Todd, O.E., Figueiredo, M.R.A., Morran, S., Soni, N., Preston, C., Kubeš, M.F., Napier, R., Gaines, T.A., 2020. Hide details Synthetic auxin herbicides: finding the lock and key to weed resistance. Plant Sci. 300, 110631.

Torra, J., Rojano-Delgado, A.M., Rey-Caballero, J., Royo-Esnal, A., Salas, M.L., De Prado, R., 2017. Enhanced 2,4-D metabolism in two resistant Papaver rhoeas populations from Spain. Front. Plant Sci. 8, 1584.

Werck-Reichhart, D., Feyereisen, R., 2000. Cytochromes P450: a success story. Genome Biol. 1 (6). REVIEWS3003. 
Yang, Q., Li, J., Shen, J., Xu, Y., Liu, H., Deng, W., Li, X., Zheng, M., 2018. Metabolic resistance to acetolactate synthase inhibiting herbicide tribenuron-methyl in Descurainia sophia L. mediated by cytochrome P450 enzymes. J. Agric. Food Chem. $66,4319-4327$.

Yasuor, H., Osuna, M.D., Ortiz, A., Saldain, N.E., Eckert, J.W., Fischer, A.J., 2009. Mechanism of resistance to penoxsulam in late watergrass [Echinochloa phyllopogon (Stapf) Koss.]. J. Agric. Food Chem. 57, 3653-3660.
Yu, Q., Powles, S.B., 2014a. Metabolism-based herbicide resistance and cross-resistance in crop weeds: a threat to herbicide sustainability and global crop production. Plant Physiol. 166, 1106-1118.

Yu, Q., Powles, S.B., 2014b. Resistance to AHAS inhibitor herbicides: current understanding. Pest Manag. Sci. 70, 1340-1350.

Yuan, J.S., Tranel, P.J., Stewart, C.N., 2007. Non-target-site herbicide resistance: a family business. Trends Plant Sci. 12, 6-13. 